\section{Health monitoring program for the control of laboratory animal diseases}

\author{
Chiara Romano, Andrea Cacciamali, \\ Silvia Dotti, Riccardo Villa
}

Istituto Zooprofilattico Sperimentale della Lombardia e dell'Emilia Romagna (IZSLER), Centro di Referenza Nazionale per i Metodi Alternativi, Benessere e Cura degli Animali da Laboratorio, Brescia, Italy

\begin{abstract}
Pathogens present in the environment are the biggest source of diseases and epidemics in the breeding of laboratory animals. In fact, the presence of microorganisms can critically influence the animal health status and, consequently, the validity and reproducibility of experimental data. In accordance with the 3 Rs principle (Refinement, Reduction, Replacement), this study is part of the Refinement concept. The FELASA guidelines, formulated with the aim of guaranteeing the best animal health state, are a valid support for researchers. In this preliminary study, health-monitoring program was carried out within the breeding of laboratory animals in IZSLER facility. The main murine viruses were analyzed through molecular biology techniques (PCR, RT-PCR) and enzyme immunoassays (indirect ELISA). The established surveillance program steadily guarantees animal health and ensures the most controlled environmental and sanitary conditions. Further investigations will be needed to develop virus control strategies.
\end{abstract}

\section{Introduction}

Pathogens present in the environment play a critical role concerning the validity and the repoducibility of experimental data and animal welfare. The protection and care of laboratory animals is a bedrock in the field of health surveillance in the breeding, for these reasons and in accordance with the 3Rs principle, ${ }^{1}$ this study is part of the Refinement concept, as by carrying out a health-monitoring program there is an improvement in animal health and environmental conditions, which are strictly dependent on the organizational and operational systems adopted in the facility. It is therefore important to establish a health surveillance program as part of a quality assurance system, with a key role in protecting animals. As mentioned in the Italian Legislative Decree 26/2014, ${ }^{2}$ the implementation of a health-monitoring surveillance is essential and necessary as it supplies: daily microbiological surveillance, use of parameters and procedures for the introduction of new subjects and action plans in the event of overt health problems. Furthermore, guidelines provided by FELASA $^{3}$ suggest that the growing number of identified pathogens requires a constant adjustment of the diagnostic procedures in order to guarantee the optimal state of animal health. For these reasons, the National Reference Center for Alternative Methods, Welfare and Care of the Laboratory Animals of IZSLER in Brescia developed a health-monitoring program and diagnostic tools for the defense and the protection of laboratory mice.

\section{Materials and Methods}

In this preliminary study, a virus surveillance program was carried out within the breeding of laboratory animals in IZSLER facility. The main murine viruses analyzed were:

Polyoma virus of mice (POLY)

Adenovirus type 1 (ADENO),

Murine Hepatitis Virus (MHV),

Murine Teilovirus (TMEV),

Parvoviruses (Minute Virus of Mice, MVM and Mouse Parvovirus MPV),

Pneumonia Virus of Mice (PVM),

Ectromelia virus (ECTV),

Polyoma virus of mice (PVM),

Sendai virus (SENDAI),

Reovirus type 3 (REO-3).

Viruses were analyzed through molecular biology techniques and enzyme immunoassays (indirect ELISA). In particular, for molecular biology analysis, organs and faeces were used. Spleens, hearts, lungs, livers and kidneys were disrupted using a lysis buffer and an automatic homogenizer, while the faeces were processed with PBS and mixed with a stirrer. RNA and DNA were extracted by an automatic spin column system and PCR internal methods were performed with specific primer pair and probes for each virus. 4 The experimental conditions for RNA virus amplifications were as following: 1 cycle of reverse transcription at $50^{\circ} \mathrm{C}$ for $20 \mathrm{~min}, 1$ cycle of initial denaturation at $95^{\circ} \mathrm{C}$ for $5 \mathrm{~min}, 40$ cycles of denaturation $\left(95^{\circ} \mathrm{C}\right.$ for $\left.15 \mathrm{sec}\right)$ and annealing/extension $\left(60^{\circ} \mathrm{C}\right.$ for $\left.45 \mathrm{sec}\right)$. The same protocol, except for the reverse
Correspondence: Chiara Romano, Istituto Zooprofilattico Sperimentale della Lombardia e dell'Emilia Romagna (IZSLER), Centro di Referenza Nazionale per i Metodi Alternativi, Benessere e Cura degli Animali da Laboratorio, Brescia, Italy.

E-mail: chiara.romano@izsler.it

Key words: Health-monitoring; 3R's principle; rodents' breeding; molecular analysis; serological analysis.

Conference presentation: this paper was presented at the Second Centro 3R Annual Meeting - 3Rs in Italian Universities, 2019, June 20-21, University of Genoa, Italy.

Received for publication: 28 October 2019.

Accepted for publication: 11 November 2019.

This work is licensed under a Creative Commons Attribution NonCommercial 4.0 License (CC BY-NC 4.0).

\section{(C) Copyright: the Author(s), 2019}

Licensee PAGEPress, Italy

Biomedical Science and Engineering 2019; 3(s3):117 doi:10.4081/bse.2019.117

transcription, was used for the DNA viruses. The quantifications of the target sequences were analyzed through a Real Time thermal cycler.

Commercial kits were purchased in order to carry out the ELISA assay for the detection of Immunoglobulins G (IgG). The serum was incubated in an adsorbed plate with each viral antigen at $37^{\circ} \mathrm{C}$ for $45 \mathrm{~min}$. The conjugate was added to the reaction plate and incubated at $37^{\circ} \mathrm{C}$ for $45 \mathrm{~min}$. The substrate was distributed in the wells and placed in the dark for $30 \mathrm{~min}$ at room temperature. Using a spectrophotometer an absorbance (OD) at $405 \mathrm{~nm}$ was read and the data was processed in order to calculate the absorbance differential $(\Delta \mathrm{OD})$.

\section{Results}

A total of 42 samples were analyzed. In Figure 1 the main results are shown. From serological analysis it was observed that the mice have been in contact with MHV, highlighting the presence of the specific MHV IgG in $42 \%$ of samples, followed by ADENO (16\%). The two Parvoviruses analyzed, MVM and MPV show $12 \%$ and $10 \%$ of prevalence, respectively, while REO-3, SENDAI, PVM and TMEV antibodies are present in less than $10 \%$ of the analyzed samples. Overlapping data were obtained from molecular biology tests, where in fact a 


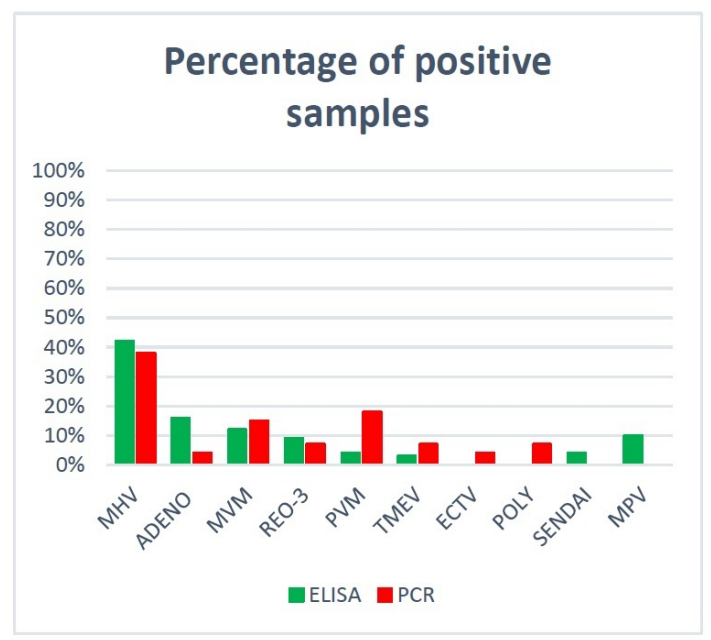

Figure 1. RT-PCR and ELISA assays results.

prevalence of MHV antigens is observed (38\%). PVM is the second predominant virus in RT-PCR (18\%), whereas the molecular detection of MVM and REO-3 replicates the ELISA assay test, showing $15 \%$ and $7 \%$ of predominance, respectively. The molecular analysis of ADENO and TMEV are in contrast with serological data (ADENO: $4 \%$ vs 16\% and TMEV: $7 \%$ vs 3\%). Finally, ECTV and POLY, whose antibodies were absent in the ELISA assay, show a prevalence of $4 \%$ and $7 \%$ of respective antigens in RT-PCR.

\section{Conclusions}

This preliminary work emphasizes the importance of welfare and care of laboratory animals in experimental research. The established surveillance program steadily guarantees animal health for the entire duration of the housing and ensures the most controlled environmental and sanitary conditions. More samples will be processed in order to perform a statistical analysis of the data obtained. However, further investigations will be needed for animal welfare monitoring and virus control strategies developing (e.g. quarantine).

\section{References}

1. Russell WMS, Burch RL. The principles of humane experimental technique. London, UK: Methuen; 1959.

2. Decreto Legislativo 4 marzo 2014, n. 26. Attuazione della direttiva 2010/63/UE sulla protezione degli animali utilizzati a fini scientifici.

3. FELASA working group on revision of guidelines for health monitoring of rodents and rabbits, Mähler Convenor M, Berard M, wt al. FELASA recommendations for the health monitoring of mouse, rat, hamster, guinea pig and rabbit colonies in breeding and experimental units. Lab Anim 2014;48:178-92.

4. BLAST (Basic Local Allignment Search Tool). Available from: https://blast.ncbi.nlm.nih.gov/Blast.cgi 